\title{
INTERACTION OF TEOS WITH CEMENTITIOUS MATERIALS: \\ CHEMICAL AND PHYSICAL EFFECTS
}

\author{
A.M. Barberena-Fernández ${ }^{\mathrm{a}}$, P.M. Carmona-Quiroga ${ }^{\mathrm{b}}$, M.T. Blanco-Varela ${ }^{\mathrm{b},{ }^{*}}$ \\ ${ }^{\mathrm{a}}$ Facultad de Bellas Artes, Universidad Complutense de Madrid, C/Greco 2, 28040 \\ Madrid, Spain \\ ${ }^{\mathrm{b}}$ Instituto de Ciencias de la Construcción Eduardo Torroja (IETcc-CSIC), C/ Serrano \\ Galvache 4, 28033 Madrid, Spain
}

\begin{abstract}
This study explored the effectiveness of tetraethyl orthosilicate (TEOS) as a Portland cement mortar consolidant to verify whether it meets the requirements for use in cultural assets. TEOS was found to raise cement mortar strength, lower its porosity and permeability and occasion minimal alteration in its appearance, an indication of its suitability to conserve heritage mortar works.
\end{abstract}

FTIR and ${ }^{29}$ Si MAS NMR studies supported the notion that TEOS interacts with the hydrated phases of the cement, portlandite and C-S-H gel. The reaction product between portlandite and TEOS was C-S-H gel and between TEOS and C-S-H gel was a gel with longer chain.

Keywords: Calcium-Silicate-Hydrate (C-S-H); Cement paste; Mortar; ${ }^{29}$ Si MAS NMR; TEOS; Consolidant

\footnotetext{
* Corresponding author: Tel.: +34 913020440; Fax: + 34913026047

E-mail address: blancomt@ietcc.csic.es
} 


\section{Introduction}

The growing number of twentieth- and twenty-first-century sculptures in which the new materials deployed now exhibit pathologies unlike the deterioration found in the traditional artistic heritage has prompted the study of their decay and the pursuit of solutions to ensure their conservation [1].

Intervention in Portland cement mortar or concrete sculptures merits particular attention, for despite the alleged durability of these materials, flaws are beginning to appear in some cultural assets due either to intrinsic factors associated with their fabrication or extrinsic factors related to their location and maintenance.

Lack of cement mortar or concrete cohesion may induce damage ranging from initial corrosion in the steel reinforcement to the total disintegration of the sculpture. The mortar itself may also be subject to decay as a result of its exposure to the elements in aggressive environments.

A number of market consolidants have been found to be apt for conserving the stone heritage. The requirements for such products include the non-modification of the aesthetics of the work, compatibility with the constituent materials, long-term stability and the non-production of damaging by-products, for the conservation and restoration of works of art are subject to certain limits designed to ensure minimal intervention and maximum respect for the piece to be conserved or restored [2-7].

Nonetheless, the proposal and validation of mortar consolidants and their adaptation to international recommendations on heritage conservation and restoration have been 
scantly addressed in the scientific literature $[8,9]$ and the research published has focused primarily on the conservation and restoration of natural stone materials $[6,7]$.

Tetraethoxysilane (TEOS), which polymerises via hydrolysis to yield siloxane, a silicabased polymer, $[3,10]$ is a consolidant frequently used to restore various stone materials [5,11]. Hybrid or modified TEOS-based consolidants have been developed to enhance its properties as primers for the effective protection of steel against corrosion [12] or improve its lack of elasticity which favours the formation of fractures and fissures during the drying stage [13], etc.

Polymerisation begins inside a porous material with hydrolysis of the alkoxysilane groups present in the TEOS when it reacts with atmospheric moisture and the water adsorbed onto the walls of the pores, yielding silanol groups and releasing ethanol, which evaporates (1). That is followed by polymerisation of the silanol groups to form siloxanes, a process in which water is released $(2)[10,14]$. While polymerisation takes place more quickly at high humidity and temperature, greater hardening is attained at low humidity [14].

$$
\begin{aligned}
& \mathrm{Si}\left(\mathrm{OC}_{2} \mathrm{H}_{5}\right)_{4}+4 \mathrm{H}_{2} \mathrm{O} \rightarrow \mathrm{Si}(\mathrm{OH})_{4}+4 \mathrm{C}_{2} \mathrm{H}_{5} \mathrm{OH} \\
& \mathrm{Si}(\mathrm{OH})_{4} \rightarrow \mathrm{SiO}_{2}+2 \mathrm{H}_{2} \mathrm{O}
\end{aligned}
$$

According to most product specifications, hydrolysis is nearly complete within 3 weeks of treatment, although consolidation continues thereafter [15].

Natural stone is consolidated through such polymerisation, which is ongoing until all the silanol groups react, either among themselves to form a silica gel or with other silanol groups present in the substrate $[16,17]$. When used on carbonate stones the 
consolidation is less effective due to the lack of interfacial bonding between carbonate bearing minerals and siloxanes. For this reason, TEOS-based consolidants have some limitations in terms of compatibility, durability and reversibility in stones with relatively high content of carbonates and/or with some clays [18].

Hydrated Portland cement paste, a binder in mortars and concretes, consists essentially of a quasi-amorphous calcium silicate hydrate, $\mathrm{C}-\mathrm{S}-\mathrm{H}$ gel responsible for the material mechanical and bonding properties. Cement paste minority constituents include crystalline phases such as portlandite $\left(\mathrm{Ca}(\mathrm{OH})_{2}\right)$, ettringite, calcium monosulfoaluminate hydrate, etc. which contribute much less to the bonding and mechanical strength of the end product. Portland cement mortar and concrete contain pores filled with a concentrated alkali hydroxide solution that is at equilibrium with the surrounding hydration products and generally exhibits $\mathrm{pH}>12.5$.

When deteriorated concrete is consolidated with TEOS, polymerisation may be altered by the reaction between the silanol groups and the $\mathrm{Ca}^{2+}$ ions in the basic medium, possibly inducing the precipitation of C-S-H gel $[9,19]$, the strengthener that would ultimately enhance internal cohesion in damaged concrete. TEOS may likewise react with the silanol groups present in the C-S-H gel, modifying its composition and structure.

$\mathrm{C}-\mathrm{S}-\mathrm{H}$ gel nanostructure is disorderly arranged in layers that resemble the pattern found in crystalline calcium silicate hydrates such as jennite and 1.4-nm tobermorite [20-21]. . Given its short-range order, some of the most suitable techniques to study its structure are FTIR and ${ }^{29}$ Si MAS NMR [21-22]. In this study both techniques were used to determine the existence or otherwise of a chemical interaction between TEOS and the 
constituents of the hydrated cement paste by identifying differences in the spectra for the treated and untreated pastes.

This study explored the effectiveness of tetraethyl orthosilicate (TEOS) as a Portland cement mortar consolidant to verify whether it meets the aforementioned requirements for use in cultural assets, and proved that it interacts with hydrated cement paste.

\section{Experimental}

\subsection{Materials}

The chemical composition of the CEM I 42.5N/SR cement used, determined by X-ray fluorescence (XRF), is given in Table 1. Two sizes (10x10x60 mm and 60x70x10 mm) of prismatic cement paste and mortar specimens were prepared. The water:cement ratio was 1:2 (wt) and the cement:sand ratio 1:5 (wt). Fines-free $(\Phi \geq 1 \mathrm{~mm})$ standardised sand was used to favour mortar porosity. The specimens were cured underwater at $21 \pm 2{ }^{\circ} \mathrm{C}$ for 28 days.

The consolidant selected was Estel $1000 \circledR$ tetraethyl orthosilicate (hereafter TEOS) (C.T.S. Srl) [23] a transparent liquid with a density of $0.95 \mathrm{~kg} / \mathrm{L}$, a viscosity of $4.9 \mathrm{mPas}$, and a 75\% tetraethyl orthosilicate content dissolved in white spirit D40 (C.T.S. Srl; a mixture of aliphatic hydrocarbons) [24] [. According with the curing specification given by TEOS manufacturer, hydrolysis of TEOS will be finished after 3 weeks at ambient temperature and relative humidity of $95 \%$

Fig. 1 shows the FTIR spectra for liquid TEOS and the solvent (white spirit D40), while the bands observed and their interpretation are listed in Table 2. The spectral bands for 
the solvent lay in the aliphatic hydrocarbon zone [25] and overlapped with some of the bands generated by the methyl and ethyl groups present in the silicate.

\subsection{Methods}

To simulate real-life treatment procedures, consolidant product was applied dropwise to the surface of the largest side of the mortar specimens, previously cured in the said conditions for 28 days, until apparently rejected by the substrate. Apparent rejection was defined as the point when the surface remained moist for at least 1 minute. The amount of product consumed was $0.108 \mathrm{~mL} / \mathrm{cm}^{2}$ in the $10 \times 10 \times 60-\mathrm{mm}$ specimens and $0.107 \mathrm{~mL} / \mathrm{cm}^{2}$ in the $60 \times 70 \times 10-\mathrm{mm}$ samples. When applied to the mortar specimens, the consolidant could be observed with the naked eye to penetrate their entire thickness $(10 \mathrm{~mm})$. Both the treated and untreated (control) specimens were cured at $21^{\circ} \mathrm{C}$ and 95\% RH for another 3 weeks.

In order to study the most relevant properties that could be altered after the consolidation of earthmaterial heritage located outdoor, the water vapour permeability (ס) [26], low pressure water absorption coefficient [27] and colour and gloss (further to Italian standard NORMAL 43/93 recommendations) [28] were found for the 60x70x10-mm mortar specimens before and after TEOS treatment. The colorimetric coordinates were found with a Konica Minolta CM 2500d spectrophotometer with a built-in sphere for measuring solids and a wavelength range of 360 to $740 \mathrm{~nm}$. The measuring conditions established at the beginning of the trial were: colour space, $\mathrm{L}^{*} \mathrm{a} \mathrm{b}^{*}$; illuminant, D65 (in which the light source is daylight with ultraviolet radiation); and measurement angle with respect to the surface-normal plane, $10^{\circ}$. SCI 
(specular component included) and SCE (specular component excluded) measurements were recorded. Gloss on the treated and untreated surfaces was measured at an 85-degree angle using a portable Konica Minolta Multi Gloss 268 gloss meter sensitive to variations in low gloss surfaces (0-160 gloss units, GU).

The 10x10x60-mm prismatic specimens were tested for compressive and bending strength to determine the mechanical properties of the treated and untreated mortars, main objective of the treatment. The compressive trials were conducted on an Ibertest Autotest 200/10SW test frame and the bending trials on an NETZSCH 6.111.2 frame operating at 220 volts and $50 \mathrm{~Hz}$. The modulus of elasticity was determined by acoustic resonance spectroscopy (ARS), in which the signal emitted was captured with a Industrial GrindoSonic MK5 instrument and the impact was produced with a 5-mm diameter steel ball-peen hammer [29]. The signal amplification system was fitted with a microphone positioned next to the specimen to capture the sound of the hammer impact against the specimen. Both the microphone and the specimen were set onto supports to insulate them from external vibrations.

Specimen porosity was determined on a Micromeritics Autopore IV 9500 V1.05 mercury porosimeter, applying a maximum intrusion pressure of 32995.97 psia, which corresponds to a pore diameter of $0.0067 \mu \mathrm{m}$.

The consolidant was characterised with FTIR and ${ }^{29}$ Si MAS NMR before and after being reticulated for 45 days at $21{ }^{\circ} \mathrm{C}$ and a $\mathrm{RH}$ of $95 \%$. The solvent (white spirit D40) was characterised by FTIR. 
The interaction between TEOS and portlandite was studied with FTIR and ${ }^{29}$ Si MAS NMR in mixes of the two materials, with molar rate TEOS/portlandite from $1 / 1$ to $1 / 2$, placed in a Petri plate, and cured for 45 days at $21{ }^{\circ} \mathrm{C}$ and $95 \% \mathrm{RH}$.

The cement-consolidant interaction was analysed by applying TEOS to 28 -day crushed cement paste, curing the treated and untreated samples at $21^{\circ} \mathrm{C}$ and $95 \% \mathrm{RH}$ for 3 weeks and subsequently characterising the materials with FTIR and ${ }^{29}$ Si MAS NMR.

FTIR spectra were recorded on a NICOLET 600 FT-IR series spectrophotometer. Liquids were analyzed in a liquid cell. Solid samples were prepared by mixing $1 \mathrm{mg}$ of sample with $300 \mathrm{mg}$ of $\mathrm{KBr}$. Spectral analysis was performed over the wavenumber range $4000-400 \mathrm{~cm}^{-1}$ at a resolution of $4 \mathrm{~cm}^{-1}$.

The ${ }^{29} \mathrm{Si}$ MAS NMR spectra were recorded at 79.49 MHz on a Bruker AVANCE-400 spectrometer using an external magnetic field of 9.4T. Measurements were taken at 20 ${ }^{\circ} \mathrm{C}$ and the samples were spun around the magic angle (54 $44^{\prime}$ with respect to the magnetic field) at a rate of $10 \mathrm{kHz}$. The pulse length was $\pi / 2$ per $5 \mu$ s, with 20 -second intervals between accumulated scans. The ${ }^{29} \mathrm{Si}$ chemical shifts were referred to $\left(\mathrm{CH}_{3}\right)_{4} \mathrm{Si}$.

The NMR and FTIR spectra were deconvolved with Origin software to determine the contribution of each component to the signals, assuming Gaussian distributions.

X-ray fluorescence (XRF) analysis of cement was conducted on a Philips PW 2400 spectrometer fitted with an Rh tube and PW 2540 VTC sample changer. 


\section{Results}

\subsection{Physical characterisation of treated and untreated mortars}

Table 3 gives the physical properties for the mortar (some of the data were drawn from [34]).

The mortars treated with the consolidant product exhibited much lower water vapour permeability and water absorption coefficient than the untreated specimens, with differences of $54.2 \%$ and $40.68 \%$, respectively. These results concurred with the dramatic decrease in capillary suction of concretes found in literature [35].

The treatment darkened the mortar surface somewhat and heightened its gloss slightly. At around 5, the colour variations, $\Delta \mathrm{E}^{*}\left(\Delta \mathrm{E}^{*}=\left(\Delta \mathrm{L}^{* 2}+\Delta \mathrm{a}^{* 2}+\Delta \mathrm{b}^{* 2}\right)^{1 / 2}\right)$, lay within a range regarded as acceptable by some authors [2], although according to others the naked eye can detect colour changes of over $3[37,38]$ or $2.5[36]$ units.

Both compressive and flexural strength were substantially higher in the treated mortar: by $46 \%$ and around $36 \%$, respectively. That difference concurred with the higher modulus of elasticity determined by resonance frequency and was consistent with the 26-per cent decline in total porosity induced by the treatment applied. While a very steep slide in the volume of pores $\Phi>1 \mu \mathrm{m}$ was observed (Fig. 2, Table 3), the volume of the smallest pores detectable by this technique $(<10 \mathrm{~nm})$ rose slightly. 


\subsection{Chemical interaction between TEOS and portlandite}

Firstly, the interaction of TEOS was studied with just one of the cement hydration products, portlandite, following previous studies by FTIR [9] and for the first time through ${ }^{29} \mathrm{Si}$ NMR.

Fig. 3 shows the FTIR spectra for TEOS cured for 45 days at $21 \pm 1^{\circ} \mathrm{C}$ and $95 \%$ RH as well as for the portlandite-consolidant mix cured under the same conditions.

During TEOS curing, the solvent evaporated and the silicate, when in contact with ambient moisture, hydrolysed and polymerised as described in Equations 1 and 2, respectively; i.e., after the ethanol evaporated, the $\mathrm{CH}_{3}$ and $\mathrm{CH}_{2}$ bands in the ethoxy groups comprising the TEOS nearly disappeared from the spectra. The spectrum contained bands at 3446 and $1635 \mathrm{~cm}^{-1}$, respectively attributed to the $\mathrm{O}-\mathrm{H}$ stretching vibrations and $\mathrm{H}-\mathrm{O}-\mathrm{H}$ bending vibrations generated by water; a band at around $1080 \mathrm{~cm}^{-1}$ with a shoulder at about $1165 \mathrm{~cm}^{-1}$, assigned to silica gel Si-O v vibrations, a band at around $794 \mathrm{~cm}^{-1}$ associated with Si-O $v_{1}$ vibrations and a band at $458 \mathrm{~cm}^{-1}$ related to O-Si-O bending vibrations. A band at around $949 \mathrm{~cm}^{-1}$ was interpreted to be primarily due to the Si-O stretching vibrations in residual silanol groups [10].

A comparison of the TEOS spectra to the TEOS + portlandite spectra (both cured at $\mathrm{RH}>95 \%$ ) showed that the latter, in addition to a widening of the $\mathrm{Si}-\mathrm{O} v_{3}$ band, exhibited a $24-\mathrm{cm}^{-1}$ shift toward a lower wavenumber and the absence of the silanol group band at around $949 \mathrm{~cm}^{-1}$. Deconvolving the main band in this spectrum (Fig. 3, Table 4) revealed three bands, one of which, at around $960 \mathrm{~cm}^{-1}$ was typical of the Si-O 
asymmetric stretching vibrations in gel C-S-H, while the other two wider signals might be attributable to Ca-poor gels, overlapping with bands generated by amorphous silica.

The ${ }^{29} \mathrm{Si}$ MAS NMR spectrum for TEOS cured at $21{ }^{\circ} \mathrm{C}$ and $95 \%$ RH for 45 days (Fig. 4) exhibited two intense bands centred at -102 and $-111 \mathrm{ppm}$, characteristic of $\mathrm{Q}^{3}(\mathrm{Si})$ and $\mathrm{Q}^{4}(\mathrm{Si})$, i.e. Si units in planar and three-dimensional structures [39]. The presence of Si units in the $\mathrm{Q}^{3}$ configuration was an indication that under the curing conditions described, polymerisation had not concluded, corroborating the FTIR observations. The existence of an interaction between TEOS and portlandite could likewise be clearly deduced from the ${ }^{29}$ Si MAS NMR spectra (Fig. 4). The intense signal at around -85 ppm with a shoulder at around $-79 \mathrm{ppm}$ on the spectrum for the mix were respectively attributed to $\mathrm{Q}^{2}(\mathrm{Si})$ and $\mathrm{Q}^{1}(\mathrm{Si})$ units in $\mathrm{C}-\mathrm{S}-\mathrm{H}$ gel chains [40], along with $\mathrm{Q}^{3}(\mathrm{Si})(\approx-100$ ppm) and $\mathrm{Q}^{4}(\mathrm{Si})(\approx-111 \mathrm{ppm})$ units characteristic of the polymerised consolidant.

\subsection{Chemical interaction between hydrated cement paste and TEOS}

The consolidant was applied to crushed hydrated cement paste specimens (whose FTIR and ${ }^{29}$ Si MAS NMR spectra are shown in Fig. 5 and 6) to avoid the overlapping between the signals generated by the quartz present in the aggregate and the bands attributed to the C-S-H gel and TEOS.

The FTIR spectrum for the control cement paste (Fig. 5) exhibited a portlandite O-H stretching band at around $3640 \mathrm{~cm}^{-1}$; water $\mathrm{O}-\mathrm{H}$ stretching and $\mathrm{H}-\mathrm{O}-\mathrm{H}$ bending bands at 3436 and $1630 \mathrm{~cm}^{-1}$; calcite C-O v, $\mathrm{C}-\mathrm{O} v_{2}$ and O-C-O $v_{4}$ bands (respectively at around 1429, 874 and $712 \mathrm{~cm}^{-1}$ ); a calcium sulfoaluminate hydrate $\mathrm{S}-\mathrm{O} v_{3}$ vibration band at 
around $1117 \mathrm{~cm}^{-1}$; and C-S-H gel Si-O $v_{3}$, Si-O $v_{1}$ and O-Si-O $v_{4}$ bands, respectively at around 986,823 and $465 \mathrm{~cm}^{-1}$.

The intensity of the portlandite $\mathrm{O}-\mathrm{H}$ stretching band at $3641 \mathrm{~cm}^{-1}$ was lower on the spectrum for the treated paste than on the spectrum for the control. The signal in the $1100-900 \mathrm{~cm}^{-1}$ region of the spectrum, characteristic of the silicate Si-O v vibration attributed to C-S-H gel was observed to intensify and widen to higher wavenumbers, overlapping with the sulfoaluminate $\mathrm{S}-\mathrm{O} v_{3}$ vibrations (Fig. 5).

According to the deconvolution data given in Table 4 for the main Si-O v v vibration band on both spectra (Fig. 5), the presence of an additional component on the spectrum for the treated paste (at around $1054 \mathrm{~cm}^{-1}$ ) would be required for convergence to be reached for the fit. The position of that additional band, close to the position of the signal found in the deconvolution of the TEOS + portlandite spectrum (Fig. 3, Table 4), might suggest that it was the result of the interaction between TEOS and the portlandite in the hydrated paste.

The ${ }^{29} \mathrm{Si}$ NMR spectra for the untreated paste (Fig. 6) exhibited signals denoting: $\mathrm{Q}^{0}$ or isolated tetrahedra (bands from -67.3 to $-76.7 \mathrm{ppm}$ associated with anhydrous alite and belite); $\mathrm{Q}^{1}$, chain-end tetrahedra or dimers (signal at -79.2); and $\mathrm{Q}^{2}$, mid-chain groups (at $\approx-85 \mathrm{ppm}$ ), both of whose adjacent tetrahedra contained silicon atoms. According to the literature, the latter two, attributed to the C-S-H gel formed during cement hydration $[40,41]$ overlapped with a third signal at around $-81 \mathrm{ppm}$, associated with $\mathrm{Q}^{2}(1 \mathrm{Al})$ units, i.e., mid-chain groups in which one of the adjacent tetrahedra contained aluminium. For a satisfactory fit to the curve profile, moreover, spectrum deconvolution 
called for the inclusion of a component at around $-82.8 \mathrm{ppm}$, which might be interpreted to be due to bridging silicons $\left(\mathrm{Q}^{2}(\mathrm{~L})\right.$ units) [42].

The ${ }^{29} \mathrm{Si}$ NMR spectrum for the TEOS-treated cement paste contained the same bands as described above for the control, but the profile was greatly altered, particularly in the region attributed to the Si in C-S-H gel. Significant band widening was observed in that region, with overlapping with the signals attributed to $\mathrm{Q}^{1}(\approx-79 \mathrm{ppm})$ and $\mathrm{Q}^{2}(1 \mathrm{Al})$ $(\approx-81 \mathrm{ppm})$ units. The intensity of the bands generated by $\mathrm{Q}^{2}(\approx-85 \mathrm{ppm})$ and $\mathrm{Q}^{2}(\mathrm{~L})$ $(\approx-83 \mathrm{ppm})$ was substantially higher on the spectrum for the treated than the untreated paste. No bands were observed at around $-90,-100$ or $-110 \mathrm{ppm}$, an indication that the hydrolysed TEOS failed to polymerise into $\mathrm{Q}^{3}$ (flat structures) or $\mathrm{Q}^{4}$ (three-dimensional structures) units. Spectrum deconvolution (Table 5) denoted a decline in $\mathrm{Q}^{0}$ units in the treated pastes due to the additional Si from TEOS. At the same time, the aforementioned widening of the band that overlapped the signals generated by $\mathrm{Q}^{1}$ and $\mathrm{Q}^{2}(1 \mathrm{Al})$ units was due primarily to a decline in the number of $\mathrm{Q}^{1}$ units, while no material variation was observed in the $\mathrm{Q}^{2}(1 \mathrm{Al})$ units. The rises in the $\mathrm{Q}^{2}$ and $\mathrm{Q}^{2}(\mathrm{~L})$ units, which were $\approx 35$ and $30 \%$, respectively, translated into a longer C-S-H mean chain length in the presence of the consolidant, from 5.17 to 8.27 , as estimated with the Richardson equations.

\section{Discussion}

Concrete sculpture conservation measures must be implemented with utmost care to ensure that no artistic features are altered in the process: tasks such as chipping off and repair of damaged areas and replacement with new material that constitute standard 
intervention practice in other types of concrete works are not applicable. Moreover, the treatment may not under any circumstances alter colour and the product used must be compatible with the material to be repaired $[2,3,6,7,15]$.

Further to the data in Table 3, TEOS is an effective consolidant for Portland cement mortars, reducing porosity and mean pore size and substantially raising bending and compressive strength as well as the modulus of elasticity.

Nonetheless, TEOS induces some surface darkening and heightens gloss slightly, for a total colour variation, $\Delta \mathrm{E}$, of 5 units, i.e., in a range either imperceptible [2] or barely perceptible [25] to the naked eye as it has been reported in concretes [28].

The use of TEOS reduces the vapour permeability and low pressure water absorption coefficient of the material, both undesirable effects according to the recommendations in place [15]. The literature describes damage to heritage materials whose physical properties were altered by conservation treatments [43]. Products that clog pores or form a thin surface film ultimately cause scaling and peeling as a result of salt crystallisation in the weakest zone, i.e., at the consolidant-original material interface, which hinders the necessary vapour flow $[5,44]$.

In the mortars studied here, TEOS did not seal or consolidate the surface alone, but penetrated the pore network, and while reducing pore size, it did not generate a fragile treated-untreated material interface. Moreover, lower porosity and permeability would protect mortar from the ingress of aggressive external agents such as $\mathrm{CO}_{2}, \mathrm{SO}_{4}{ }^{2-}, \mathrm{Cl}^{-}$, 
$\mathrm{NO}_{3}{ }^{-}$and even moisture, which constitutes a high risk factor in reinforced concrete sculptures.

A comparison of the ${ }^{29} \mathrm{Si}$ MAS NMR spectra for paste with and without TEOS revealed no bands attributable to $\mathrm{Q}^{3}$ or $\mathrm{Q}^{4}$ units, respectively indicative of the presence of branching and cross-linking TEOS silicons, while modifications were visible in the -79 to $-85 \mathrm{ppm}$ region. According to the the ${ }^{29} \mathrm{Si}$ MAS NMR spectrum chemical shift values reported by Besland and Sassi [45-47] for monomeric TEOS and its polymerised and hydrolysed species, listed in Table 6, if TEOS hydrolysed and polymerised pursuant to the process described in Equations 1 and 2, the species that might be present and explain such modifications described would be:

$$
\begin{array}{ll}
\mathrm{Si}(\mathrm{OEt})_{4}\left(Q^{0}(\mathrm{Si})-82.2 \mathrm{ppm}\right) ; & \mathrm{Si}(\mathrm{OH})(\mathrm{OEt})_{3}\left(Q^{0}(\mathrm{Si})-78 \mathrm{ppm}\right) ; \\
\mathrm{Si}(\mathrm{OEt})_{3} \mathrm{O}-\left(Q^{1}(\mathrm{Si})-86.9 \mathrm{ppm}\right) ; & \mathrm{Si}(\mathrm{OH})(\mathrm{OEt})_{2} \mathrm{O}-\left(\mathrm{Q}^{1}(\mathrm{Si})-83.9 \mathrm{ppm}\right) ; \\
\mathrm{Si}(\mathrm{OH})_{2}(\mathrm{OEt}) \mathrm{O}-\left(\mathrm{Q}^{1}(\mathrm{Si})-80.9 \mathrm{ppm}\right) ; & \mathrm{Si}(\mathrm{OH})_{3}(\mathrm{O}-)\left(Q^{1}(\mathrm{Si})-78 \mathrm{ppm}\right) .
\end{array}
$$

Their presence would denote incomplete hydrolysis, and the Si-OEt, ethoxy group $\mathrm{CH}_{3}$ and $\mathrm{CH}_{2}$ vibrations would have to appear on the FTIR spectra, a development not experimentally observed. Moreover, polymerisation would be scant and insufficient to explain the rise in mortar mechanical strength observed.

Another possibility would be that TEOS might hydrolyse as per Equation 1 but without polymerising as described in Equation 2. During polymerisation, silanol groups might react with portlandite or with the $\mathrm{Ca}^{2+}$ ion present in the aqueous solution that fills the pore network in the mortar, leading to the precipitation of a calcium silicate. 
Moropoulou et al. [19] using electron microscopy (TEM), identified C-S-H gel as the reaction product of a saturated portlandite solution to which they added variable amounts of TEOS. Sandrolini et al. [9] also demonstrated the formation of C-S-H compounds in mixtures of TEOS and slaked lime.

Further to the ${ }^{29} \mathrm{Si}$ MAS NMR findings described in section 3.3, the presence of portlandite modified TEOS polymerisation substantially, and the reaction between the two compounds yielded a C-S-H gel. The FTIR spectrum for the product obtained exhibited a shift in the main band, attributed to Si-O asymmetric stretching vibrations, to lower wavenumbers (from 1080 to $1056 \mathrm{~cm}^{-1}$ ). In the C-S-H gel for the two cements, that band was wide and located at around $970 \mathrm{~cm}^{-1}$, and both its profile and position depended on gel structure. In a study using synthetic gels, Yu et al. [48] observed that the band shifted to higher wavenumbers as the $\mathrm{Ca} / \mathrm{Si}$ ratio declined, due to the concomitant rise in chain polymerisation and number of $Q^{2}$ units present [49]. GarcíaLodeiro et al. [50] associated the position of the band with medium $\mathrm{pH}$ and found it to lie at $\approx 1011 \mathrm{~cm}^{-1}$ in gels obtained at $\mathrm{pH}>11$. Sáez del Bosque et al. [51] studied band profile in gels obtained by $\mathrm{C}_{3} \mathrm{~S}$ hydration at 25,40 and $65^{\circ} \mathrm{C}$ and concluded that higher temperatures furthered the formation of intensely polymerised gels with jennite-type structures. The effect on FTIR spectra was band widening toward higher wavenumbers and a rise in the intensity of the shoulder at around $1076 \mathrm{~cm}^{-1}$ in the main band.

The FTIR spectrum profile for the product formed in the portlandite-TEOS reaction (Fig. 3) was similar to the profile for synthetic gels with a $\mathrm{Ca} / \mathrm{Si}$ ratio $\approx 0.4-0.6$, suggesting their presence $[42,48,50]$. 
The relative intensity of the Si-O $v_{3}$ band at around $990 \mathrm{~cm}^{-1}$ (compared to S-O v $v_{3}$ band at $1127 \mathrm{~cm}^{-1}$ ) on the spectrum for the treated paste was much higher than on the control paste spectrum (Fig. 5). Furthermore, deconvolution revealed the presence of another intense band at $1054 \mathrm{~cm}^{-1}$, overlapping with the Si-O $v_{3}$ band, which might be generated by two C-S-H gels, one resulting from cement silicate hydration and the other from the reaction between TEOS and $\mathrm{Ca}(\mathrm{OH})_{2}$, respectively.

Moreover, the silanol groups in the hydrolysed TEOS might have also reacted with dimeric $\mathrm{Q}^{1}$ silanol groups or the end of the C-S-H gel chain in the hydrated cement paste, lengthening the chain [52].

A comparison of the ${ }^{29} \mathrm{Si}$ MAS NMR spectrum profiles for the two pastes (Fig. 6) showed that after TEOS treatment, the $\mathrm{Q}^{1}$ signals declined relative to the $\mathrm{Q}^{2}$ signals and more specifically that the $\mathrm{Q}^{1} / \mathrm{Q}^{2}(1 \mathrm{Al})$ ratio dropped, denoting consumption of the $\mathrm{Q}^{1} \mathrm{Si}$ species as a result of the C-S-H gel-TEOS interaction. The band at around $-83 \mathrm{ppm}$ was also observed to grow. That signal has been detected in gels with low $\mathrm{Ca} / \mathrm{Si}$ ratios $(\approx 0.66)[53]$, although other researchers $[49,54]$ did not relate it to gel composition.

García Lodeiro et al. [38] recently concluded that the band is generated by hydroxylated Si located in bridging tetrahedra on the C-S-H gel chain $\left(Q^{2}(\mathrm{~L})\right)$ and can be distinguished from the rest of the $\mathrm{Q}^{2}$ units in gels with $\mathrm{MCL}>8$ and $\mathrm{Ca} / \mathrm{Si}$ ratios $<1$ via ${ }^{29} \mathrm{Si}$ MAS NMR. According to a ${ }^{1} \mathrm{H}^{29} \mathrm{Si}$ CP NMR spectrum [42], the aforementioned signal would be associated with silicon atoms bonded to silanol groups, consequently the $\mathrm{Q}^{2}(\mathrm{~L})$ resulting from the interaction between TEOS and the original C-S-H gel. 
The C-S-H gel in the paste treated with TEOS had a MCL of 8.27, i.e., three links more than the untreated paste. That, in conjunction with the relative decline in the bands attributable to $\mathrm{Q}^{1}$ groups, was an indication of a strong chemical reaction between TEOS and C-S-H.

\section{Conclusions}

The use of TEOS as a cement mortar consolidant improves mechanical strength and lowers porosity and permeability, while inducing no substantial alteration in colour or gloss. These findings suggest that it may be apt for use in the conservation of twentieth and twenty-first century sculptures or other heritage works made of mortar or concrete.

Mortar consolidation is the result of the reaction between TEOS and the hydrated phases of the cement, namely portlandite and C-S-H gel.

The presence of portlandite was shown here to modify TEOS polymerisation (at high $\mathrm{RH})$, and the reaction product proved to be C-S-H gel.

TEOS also interacts with the C-S-H gel formed in hydrated cement paste, giving rise to gels with longer chains than in the control cement.

\section{Acknowledgements}


Funding from the Spanish Ministry of Education and Science (Project CONSOLIDER CSD2007-00058) and the Regional Government of Madrid (Geomaterials Programme S2009/MAT-1629) is gratefully acknowledged. The authors would also like to thank CTS Europe for providing the consolidant and the white spirit.

\section{References}

[1] Han Young Moon, Dong Gu Shin, Doo Sun Choi. Evaluation of the durability of mortar and concrete applied with inorganic coating material and surface treatment system. Constr Build Mater 2007: 21:362-369.

[2] Sasse HR, Snethlage R. Methods for the evaluation of stone conservation treatments. In: Baer NS, Snethlage R, editors. Saving our Cultural Heritage: The Conservation of Historic Stone Structure, Dahlem Workshop Reports. Chichester: Wiley \& Sons, 1997. p. 223-243. [3] Ferreira Pinto AP, Delgado Rodrigues J. Consolidation of carbonate stones: Influence of treatment procedures on the strengthening action of consolidants. J Cult Herit 2012:13:154166.

[4] Rodríguez-Maribona I, Zalbide M, Garcia Garmilla F, Ibañez JA, Garín S. Conservation study of the stone material used in the Culture House of Almirante Oquendo in San Sebastian. Mater Construcc 1999:49:19-30.

[5] Pápay Z, Török A. Physical changes of porous Hungarian limestones related to silicic acid ester consolidant treatments. Geol Soc Sp Publi 2010: 331:147-155.

[6] Ferreira AP, Delgado J. Stone consolidation: The role of treatment procedures. J Cult Herit 2008:9:38-53.

[7] Wheeler G, Goins ES. Alkoxysilanes and the Consolidation of Stone (Research in conservation). Los Angeles: Getty Publications, 2005. 
[8] Carmona-Quiroga PM, Martínez-Ramírez S, Sánchez de Rojas MI, Blanco-Varela MT. Surface water repellent-mediated change in lime mortar colour and gloss. Constr Build Mater 2010:24: 2188-2193.

[9] Sandrolini F, Franzoni E, Pigino B. Ethyl silicate for surface treatment of concrete - Part I: Pozzolanic effect of ethyl silicate. Cem Concr Comp 2012:34:306-312.

[10] Rubio F, Rubio J, Oteo JL. A FT-IR study of the hydrolysis of tetraethylorthosilicate (TEOS). Spectrosc Lett 1998:31:199-219.

[11] Thiel M-J. Conservation of Stone and other Materials. Proceedings of the RILEM/UNESCO Congress. London: E \& F N Spon, 1993.

[12] Parashar G, Srivastava D, Kumar P. Ethyl silicate binders for high performance coatings. Prog Org Coat 2001:42:1-14.

[13] Zárraga R, Cervantes J, Salazar-Hernandez C, Wheeler G. Effect of the addition of hydroxyl-terminated polydimethylsiloxane to TEOS-based stone consolidants. J Cult Herit 2010: 11:138-144.

[14] Piacenti F, Carbonell RG, Camaiti M, Henon FE, Puppichini E. Protective Materials for Stone-Effects on Stone Permeability and Gas Transport. In: Laurenzi Tabasso, editor. Methods of Evaluating Products for the Conservation of Porous Building Materials in Monuments. Rome: ICCROM, 1995. p. 373-388.

[15] Kogoma M, Tanaka K. Application of atmospheric pressure glow plasma: powder coating in atmospheric glow plasma. In: d'Agostino R, Favia P, Kawai Y, Ikegami H, Sato N, ArefiKhonsari F, editors. Advanced plasma technology. Weinheim: Wiley-VCH, 2007. p. 341-352. [16] Cabrera Garrido JM. Protection and appraisal techniques of architectural figurations in stone. In: Roig Picazo P, editor. Proceedings of the Eighth Congress of Conservation of Cultural Property. Valencia: Generalidad Valenciana, 1990. p. 329-342.

[17] Pereyra AM, Giudice CA. Ethyl silicates with different hydrolysis degree like nonflammable impregnating material for wood. Maderas. Ciencia y tecn 2008:10:113-127. 
[18] Sassoni E, Franzoni E, Pigino B, Scherer GW, Naidu S. Consolidation of calcareous and siliceous sandstones by hydroxyapatite: Comparison with a TEOS-based consolidant. J Cult Herit 2013:14: e103-108.

[19] Moropoulou A, Cakmak A, Labropoulos KC, Van Grieken R, Torfs K. Accelerated microstructural evolution of a calcium-silicate-hydrate $(\mathrm{C}-\mathrm{S}-\mathrm{H})$ phase in pozzolanic pastes using fine siliceous sources: Comparison with historic pozzolanic mortars. Cem Concr Res 2004:34:16.

[20] Taylor HFW (1986) Proposed structure for calcium silicate hydrate gel. J Am Ceram Soc 69:464-467.

[21] Richardson IG (2004). Tobermorite/jennite- and tobermorite/calcium hydroxidebased models for the structure of $\mathrm{C}-\mathrm{S}-\mathrm{H}$ : applicability to hardened pastes of tricalcium silicate, b-dicalcium silicate, Portland cement, and blends of Portland cement with blastfurnace slag, metakaolin, or silica fume. Cem Concr Res 34:1733-1777.

[22] Yu, P., Kirkpatrick, R.J., Poe, B., McMillan, P.F., Cong, X., "Structure of calcium silicate hydrate (C-S-H): Near-, Mid-, and Far-Infrared Spectroscopy”. Journal of the American Ceramic Society, 1999. 82: p. 742-748.

[23] Estel 1000 Specification sheet. C.T.S. Srl. (http://www.ctseurope.com)

[24] White Spirit D40. C.T.S. Srl. (http://www.ctseurope.com)

[25] Pretsch E, Buhlmann P Badertscher M. Structure Determination of Organic Compounds: Tables of Spectral Data. Heidelberg: Springer-Verlag Berlin, 2009.

[26] RILEM Commission 25-PEM Protection et Érosion des Monuments. Test no. II. 2. Coefficient of water conductivity ( $\delta$ ). Matériaux de Constructions 1980:13[75] :196-199. [27] RILEM Commission 25-PEM Protection et Érosion des Monuments. Test no. II. 4. Water absorption under low pressure (pipe method). Matériaux de Constructions 1980:13[75]:201-205. [28] Raccomandazione NORMAL 43/93. Misure colorimetriche di superfici opache. Rome:CNR-ICR, Comas Grafica, 1994. 
[29] Rosell J.R., Cantalapiedra I.R. Simple method of dynamic Young's modulus

determination in lime and cement mortars.Matteriales de Construcción: 2011: 61: 301: $39-48$

[30] Al-Oweini R, El-Rassy H. Synthesis and characterization by FTIR spectroscopy of silica aerogels prepared using several $\mathrm{Si}(\mathrm{OR}) 4$ and R' 'Si(OR')3 precursors. J Mol Struct 2009: 919:140-145.

[31] Min Tae Kim. Deposition kinetics of silicon dioxide from tetraethylorthosilicate by PECV. Thin Solid Films 2000: 360:60-68.

[32] Lenza RFS, Vasconcelos WL. Structural evolution of silica sols modified with formamide. Mater Res 2001: 4:175-179.

[33]Téllez L, Rubio F, Peña-Alonso R, Rubio J. Seguimiento por espectroscopia infrarroja (FTIR) de la copolimerización de TEOS (tetraetilortosilicato) y PDMS (polidimetilsiloxano) en presencia de tbt (tetrabutiltitanio). Bol Soc Esp Ceram V 2004:43: 883-890.

[34] Barberena-Fernández AM, Carmona-Quiroga PM, San Andrés-Moya M, Blanco Varela MT. Consolidation treatments for conservation of concrete sculptures. In: Rogerio-Candelera MA, Lazzari M, Cano E. Science and Technology for the Conservation of Cultural Heritage. Leidenm: CRC Press/Balkema, 2013. p. 301-304.

[35] Pigino B, Leemann A, Franzoni E, Lura P. Ethyl silicate for surface treatment of concrete Part II: Characteristics and performance. Cem Concr Comp 2012:34:313-321.

[36] Boutin F, Leroux L. Color and weight evolution of limestone protected by water repellents after a three-year ageing in urban conditions. In: Fassina V, editor. Proceedings of the 9th International Congress on Deterioration and Conservation of Stone vol. 2. Amsterdam: Elsevier Science B.V., 2000. p. 197-205.

[37] Prieto B, Ferrer P, Sanmartín P, Cárdenes V, Silva B. Color characterization of roofing slates from the Iberian Peninsula for restoration purposes. J Cult Herit 2011: 12: 420-430. 
[38] Maravelaki-Kalaitzaki P, Kallithrakas-Kontos N, Korakaki D, Agioutantis Z,

Maurigiannakis S. Evaluation of silicon-based strengthening agents on porous limestones. Prog Org Coat 2006:57:140-148.

[39] Pérez Moreno A, Jiménez-Solís C, Esquivias L, De La Rosa Fox N. Estudio mediante RMN de la hidrólisis y policondensación de TEOS bajo la acción de ultrasonidos. Bol Soc Esp Ceram V 1998: 37:13-17.

[40] Barnes JR,Clague DH, Clayden NJ, Dobson CM, Hayes CJ, Groves GW, Rodger SA. Hydration of Portland cement followed by 29Si solid-state NMR spectroscopy. J Mater Sci Lett 1985: 4:1293-1295.

[41] Richardson IG. The nature of C-S-H in hardened cements. Cem Concr Res 1999:29:11311147.

[42] García-Lodeiro I, Fernández-Jiménez A, Sobrados I, Sanz J, Palomo A. C-S-H Gels: Interpretation of ${ }^{29}$ Si MAS-NMR Spectra. J Am Ceram Soc 2012: 95:1440-1446.

[43] Clifton JR. Laboratory evaluation of stone consolidants. In: Brommelle NS, Pye EM, Smith G, Thomson G, editors. Adhesives and Consolidants, Proceedings Tenth International Congress of the International Institute for Conservation of Historic and Artistic Works. Paris: IIC, 1984. p. $151-155$.

[44] Lewin SZ. The mechanism of masonry decay through crystallization. Barkin SM, editor. Conservation of Historic Stone Buildings and Monuments. Washington D.C.: National Academy Press, 1982. p. 120-144.

[45] Besland MP. Synthese et caracterisation de composes heteropolysiloxanes : application aux membranes d'hyperfiltration. PhD Thesis, University of Montpellier, 1989.

[46] Sassi Z, Bureau JC, Bakkali A. Structural characterization of the organic/inorganic networks in the hybrid materials (TMOS-TMSM-MMA). Vib Spectrosc 2002:28: 251-262.

[47] Sassi Z, Bureau JC, Bakkali A. Spectroscopic study of TMOS-TMSM-MMA gels: Previously identification of the networks inside the hybrid material. Vib Spectrosc 2002:28:299318. 
[48] Yu P, Kirkpatrick RJ, Poe B, McMillan PF, Cong X. Structure of calcium silicate hydrate (C-S-H): Near-, mid-, and far-infrared spectroscopy. J Am Ceram Soc 1999: 82:742-748.

[49] Cong X, Kirkpatrick RJ. ${ }^{29}$ Si MAS NMR study of the structure of calcium silicate hydrate. Adv Cement Base Mater 1996:3:144-156.

[50] García-Lodeiro I, Fernández-Jiménez A, Blanco MT, Palomo A. A FTIR study of the solgel synthesis of cementitious gels: C-S-H and N-A-S-H. J Sol-Gel Sci Techn 2008:45:63-72. [51] Sáez del Bosque IF, Martínez-Ramírez S, Blanco-Varela MT. FTIR Study of the effect of temperature and nanosilica on the nanostructure of C-S-H gel formed by tricalcium silicate hydration. Constr Build Mater 2014:52: 314-323.

[52] Carmona-Quiroga PM, Martínez-Ramírez S, Sobrados I, Blanco-Varela MT. Interaction between two anti-graffiti treatments and cement mortar (paste). Cem Concr Res 2010:40:723730.

[53] Faucon P, Delaye JM, Virlet J, Jacquinot JF, Adenot F. Study of the structural properties of the C-S-H(I) by molecular dynamics simulation. Cem Concr Res 1997:27:1581-1590.

[54] Chen JJ, Thomas JJ, Taylor HFW, Jennings HM. Solubility and structure of calcium silicate hydrate. Cem Concr Res 2004:34:1499-1519. 


\section{FIGURE CAPTIONS}

Fig. 1. Fourier transform infrared spectra for the consolidant, TEOS, and the solvent, white spirit D40, in the $4000-400 \mathrm{~cm}^{-1}$ range.

Fig. 2. Pore size distribution in the cement mortar before (control) and after application of TEOS.

Fig. 3. Infrared spectra for TEOS and the TEOS + portlandite mix: on the right, deconvolved spectra in approximately the $1400-800 \mathrm{~cm}^{-1}$ range.

Fig. 4. ${ }^{29}$ Si MAS NMR spectra for TEOS and a TEOS + portlandite mix, cured for 45 days at $95 \% \mathrm{RH}$.

Fig. 5. FTIR spectrum for humidity chamber-cured cement paste with and without TEOS: on the right, deconvolved spectra between approximately 1300 and $800 \mathrm{~cm}^{-1}$. Fig. $6 .{ }^{29}$ Si MAS NMR spectra for the 45-day hydrated cement paste with and without TEOS.

Tabla 1. Análisis químico del cemento CEM I 42.5N/SR expresado en óxidos. PC* = pérdida por calcinación a $1000^{\circ} \mathrm{C}$

\begin{tabular}{|c|c|c|c|c|c|c|c|c|c|c|c|c|}
\hline (\%) & $\mathbf{S i O}_{2}$ & $\mathbf{A l}_{2} \mathbf{O}_{3}$ & $\mathbf{F e}_{2} \mathbf{O}_{3}$ & $\mathbf{M n O}$ & $\mathbf{M g O}$ & $\mathbf{C a O}$ & $\mathbf{S O}_{3}$ & $\mathbf{N a}_{2} \mathbf{O}$ & $\mathbf{K}_{2} \mathbf{O}$ & $\mathbf{T i O}_{2}$ & $\mathbf{P}_{2} \mathbf{O}_{5}$ & $\mathbf{P C}^{*}$ \\
\hline CEM I N/SR & 19.01 & 4.06 & 4.73 & 0.03 & 1.64 & 62.4 & 3.19 & 0.07 & 0.66 & 0.23 & 0.04 & 3.02 \\
\hline
\end{tabular}


Table 2. Infrared spectrum band assignment for liquid TEOS in the 4000-400-cm ${ }^{-1}$ range (Fig. 1) $(v=$ stretching; $\delta=$ bending; $*=$ reticulated TEOS $)$

\begin{tabular}{lll}
\hline TEOS & Functional group & Ref. \\
\hline $2976-2897$ & $v$ C-H & {$[10,30,31]$} \\
$1445-1297$ & $\delta$ C-H & {$[10,30,31]$} \\
1167 & $v$ Si-O-C (v Si-O-Si*) & {$[32]([30])$} \\
1103 & $v$ Si-O-C & {$[33]$} \\
1081 & $v$ Si-O-C, v Si-O-Si & {$[30,31,33]$} \\
971 & $v$ Si-O(H) & {$[10,30]$} \\
797 & $v$ Si-O & {$[30,33]$} \\
669 & $v$ Si-O-Si & {$[30]$} \\
469 & $\delta$ O-Si-O & {$[10,30,31]$} \\
\hline
\end{tabular}

Table 3 Physical properties of cement mortars before and after treatment with TEOS (standard deviation).

\begin{tabular}{|c|c|c|c|c|}
\hline & & Uncoated & Treated & $\begin{array}{l}\text { Increase } \\
(\%)\end{array}$ \\
\hline \multicolumn{2}{|c|}{$\begin{array}{l}\text { Vapour permeability }(\mathrm{kg} / \mathrm{m} \mathrm{s} \\
\mathrm{Pa} \text { ) }\end{array}$} & $1.901715 .10^{-12}$ & & -54.2 \\
\hline \multicolumn{2}{|c|}{$\begin{array}{l}\text { Water absort. coefficient ( } \mathrm{kg} / \mathrm{m}^{2} \\
\mathrm{~h} \text { ) }\end{array}$} & 1.77 & & -40.68 \\
\hline $\mathrm{Hg}$ & Total $(\%)$ & 12.85 & 9.47 & -26 \\
\hline porosity & $\leq 1 \mu \mathrm{m}$ & 7.76 & 7.57 & \\
\hline \multirow{4}{*}{ Colour } & $\mathrm{L}^{*}$ & $73.75(1.26)$ & $68.88(1.17)$ & \\
\hline & $a^{*}$ & $0.40(0.03)$ & $0.50(0.06)$ & \\
\hline & $b^{*}$ & $5.65(0.25)$ & $6.78(0.55)$ & \\
\hline & $\Delta \mathrm{E}^{*}$ & - & $5.03(1.01)$ & \\
\hline \multicolumn{2}{|c|}{ Gloss units $\left(85^{\circ}\right)$} & $0.17(0.07)$ & $0.30(0.05)$ & \\
\hline \multicolumn{2}{|c|}{ Resistencia a la compresión } & $37.71(4.56)$ & $55.15(4.00)$ & +46 \\
\hline \multicolumn{2}{|c|}{ Resistencia a la flexotracción } & $7.88(0.78)$ & $10.72(0.89)$ & +36 \\
\hline \multicolumn{2}{|c|}{ Elastic modulus (GPa) } & 31.51 & 36.27 & +15.11 \\
\hline
\end{tabular}


Table 4 Percentage areas of the components on the infrared spectra for TEOS, the TEOS + portlandite mix, and the treated and untreated cement pastes (samples cured in humidity chamber), between approximately 1400 and $800 \mathrm{~cm}^{-1}$.

\begin{tabular}{|c|c|c|c|c|}
\hline \multirow{2}{*}{$\begin{array}{l}\text { sample } \\
\text { TEOS }\end{array}$} & \multicolumn{4}{|c|}{ Frecuency $\left(\mathrm{cm}^{-1}\right) / \operatorname{Area}(\%)$} \\
\hline & 940 & 1064 & & 1181 \\
\hline & 18 & 37 & & 45 \\
\hline \multirow{2}{*}{$\mathrm{TEOS}+\mathrm{Ca}(\mathrm{OH})_{2}$} & 960 & 1048 & & 1170 \\
\hline & 14 & 44 & & 42 \\
\hline \multirow{2}{*}{ Cement paste } & 999 & & 1127 & \\
\hline & 60 & & 40 & \\
\hline \multirow{2}{*}{ Cement paste + TEOS } & 976 & 1054 & 1120 & 1160 \\
\hline & 41 & 27 & 16 & 16 \\
\hline
\end{tabular}

Table $5 \mathrm{C}-\mathrm{S}-\mathrm{H}$ gel in cement paste with and without TEOS: absolute and percentage values of signals on 29Si MAS NMR spectra and mean chain length (MCL).

\begin{tabular}{ccccc|ccc}
\hline & \multicolumn{2}{c}{ Untreated } & \multicolumn{2}{c|}{ Treated } & C-S-H & Untreated & Treated \\
& $\delta(\mathbf{p p m})$ & Area \% & $\boldsymbol{\delta}(\mathbf{p p m})$ & Area \% & signals & $\%$ & $\%$ \\
\hline $\mathrm{Q}^{0}$ & -69.6 & 5.8 & -69.6 & 3.5 & $\mathrm{Q}^{1}$ & 42.57 & 26.95 \\
$\mathrm{Q}^{0}$ & -71.6 & 13.6 & -71.7 & 10.7 & $\mathrm{Q}^{1}(1 \mathrm{Al})$ & 20.28 & 22.97 \\
$\mathrm{Q}^{0}$ & -73.9 & 16 & -73.9 & 14 & $\mathrm{Q}^{2}(\mathrm{~L})$ & 4.95 & 6.48 \\
$\mathrm{Q}^{0}$ & & & -76.1 & 3.7 & $\mathrm{Q}^{2}$ & 32.20 & 43.59 \\
$\mathrm{Q}^{1}(\mathrm{C}-\mathrm{S}-\mathrm{H})$ & -76.7 & 7.3 & & & & & \\
$\mathrm{Q}^{1}(\mathrm{C}-\mathrm{S}-\mathrm{H})$ & -79 & 20.2 & -79.1 & 18.3 & $\mathrm{LMC}$ & 5.17 & 8.27 \\
$\mathrm{Q}^{2}(1 \mathrm{Al})(\mathrm{C}-\mathrm{S}-\mathrm{H})$ & -81.1 & 13.1 & -81 & 15.6 & & & \\
$\mathrm{Q}^{2}(\mathrm{~L})(\mathrm{C}-\mathrm{S}-\mathrm{H})$ & -82.8 & 3.2 & -83.2 & 4.4 & & & \\
$\mathrm{Q}^{2}(\mathrm{C}-\mathrm{S}-\mathrm{H})$ & -85.2 & 20.8 & -85.6 & 29.6 & & & \\
\hline
\end{tabular}


Table 6. ${ }^{29} \mathrm{Si}$ MAS NMR signals for ethyl silicate and its silanol species [45-47]

\begin{tabular}{lllll}
\hline Group & Signal $(\mathbf{p p m})$ & $\mathbf{Q}^{\mathbf{n}}(\mathbf{S i})$ & Group & Signal (ppm) \\
\hline $\mathrm{Si}(\mathrm{OEt})_{4}$ & -82.2 & $\mathbf{Q}^{\mathbf{0}}(\mathbf{S i})$ & $\mathrm{Si}(\mathrm{OH})_{4}$ & $-65 \mathrm{a}-67$ \\
$\mathrm{Si}(\mathrm{OEt})_{3} \mathrm{O}-$ & -86.9 & $\mathbf{Q}^{\mathbf{1}}(\mathrm{Si})$ & $\mathrm{Si}(\mathrm{OH})_{3}(\mathrm{O}-)$ & -78 \\
$\mathrm{Si}(\mathrm{OEt})_{2}(\mathrm{O}-)_{2}$ & -96.7 & $\mathbf{Q}^{2}(\mathrm{Si})$ & $\mathrm{Si}(\mathrm{OH})_{2}(\mathrm{O}-)_{2}$ & -92 \\
$\mathrm{Si}(\mathrm{OEt})(\mathrm{O}-)_{3}$ & -100.3 & $\mathbf{Q}^{3}(\mathrm{Si})$ & $\mathrm{Si}(\mathrm{OH})(\mathrm{O}-)_{3}$ & -98 \\
$\mathrm{Si}(\mathrm{O}-)_{4}$ & -110.7 & $\mathbf{Q}^{4}(\mathrm{Si})$ & $\mathrm{Si}(\mathrm{O}-)_{4}$ & -110.7 \\
\hline
\end{tabular}

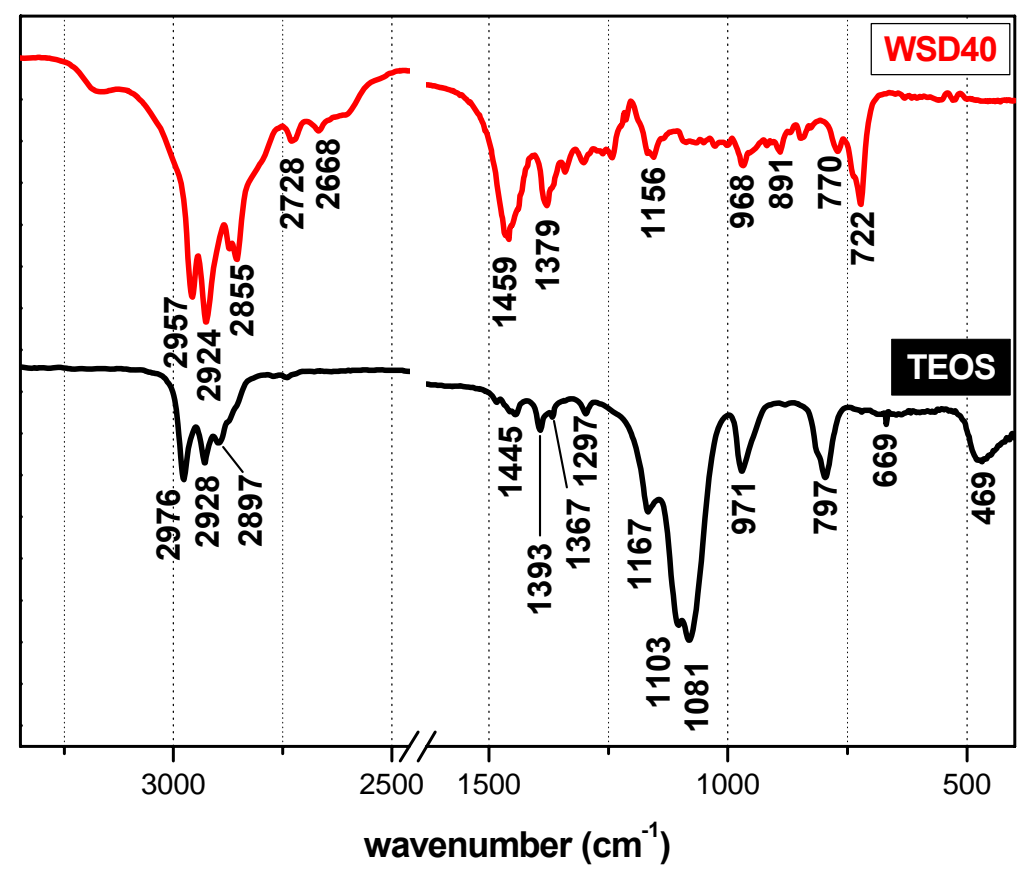

Fig. 1. Fourier transform infrared spectra for the consolidant, TEOS, and the solvent, white spirit D40, in the $4000-400 \mathrm{~cm}^{-1}$ range. 


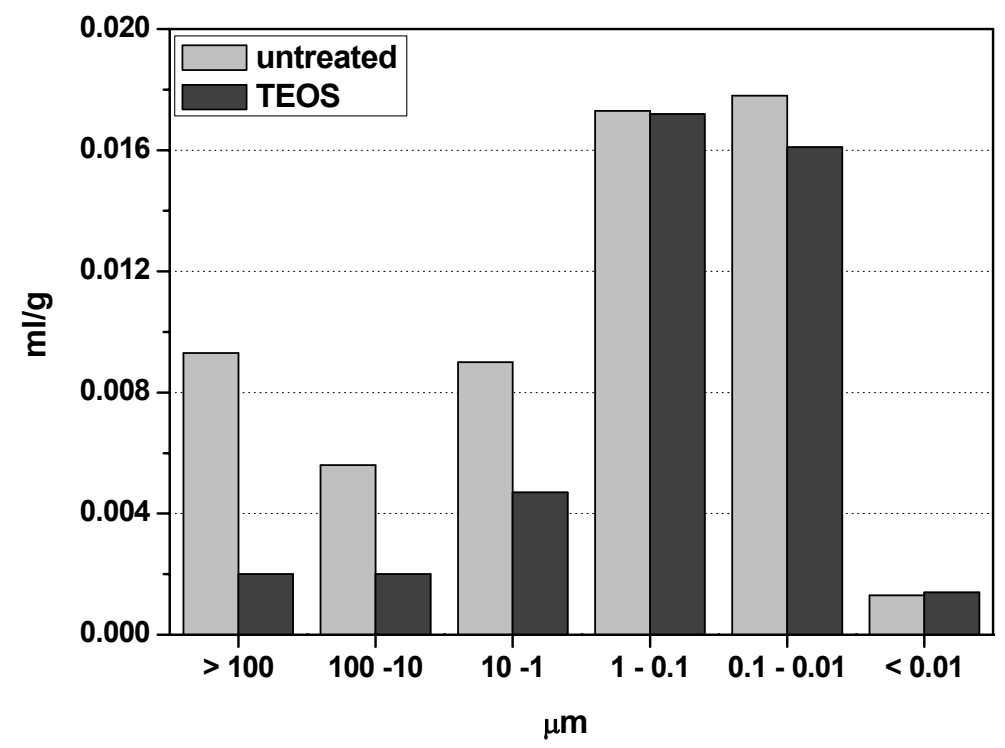

Fig. 2. Pore size distribution in the cement mortar before (control) and after application of TEOS.
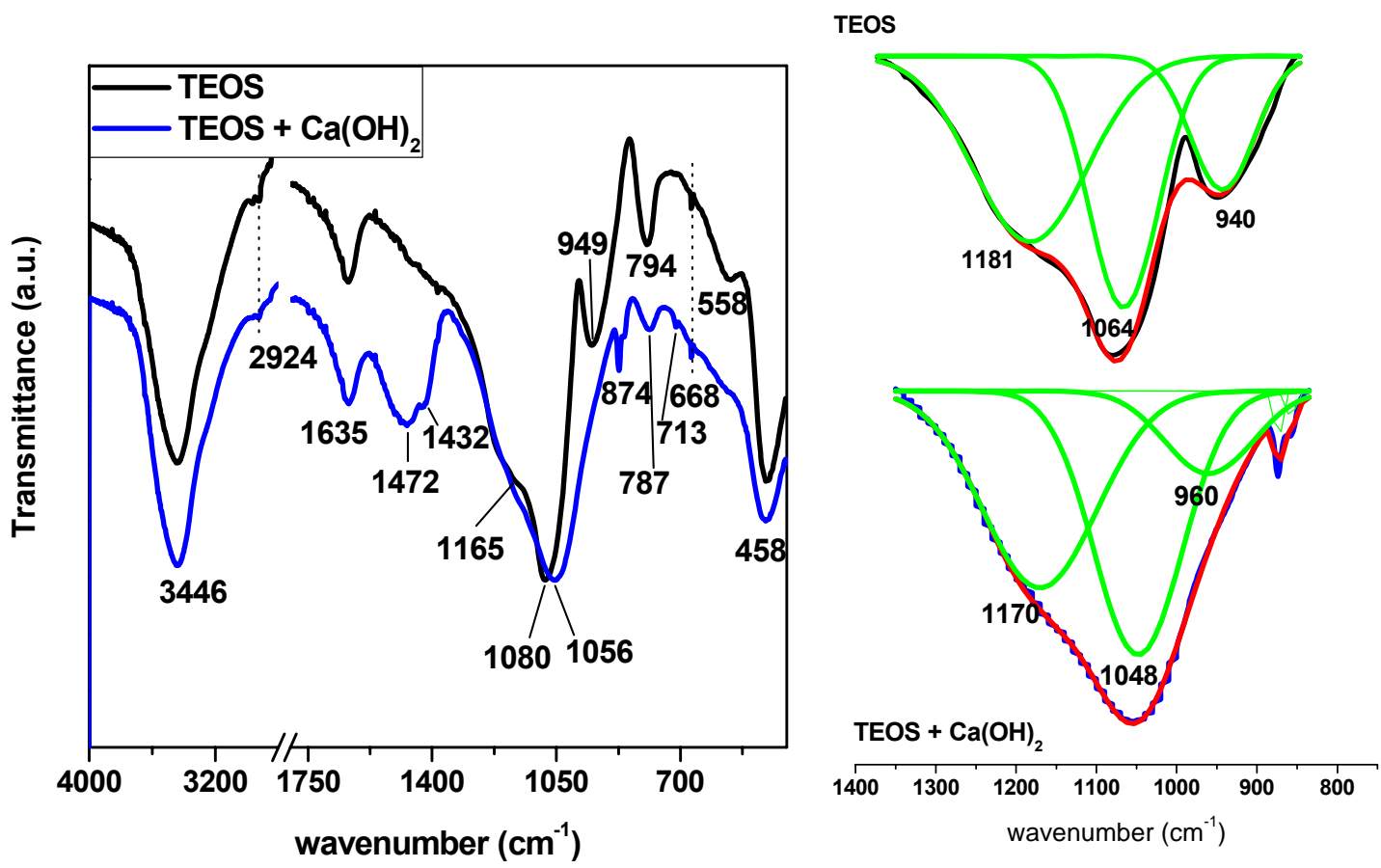

Fig. 3 Infrared spectra for TEOS and the TEOS + portlandite mix: on the right, deconvolved spectra in approximately the $1400-800 \mathrm{~cm}-1$ range. 


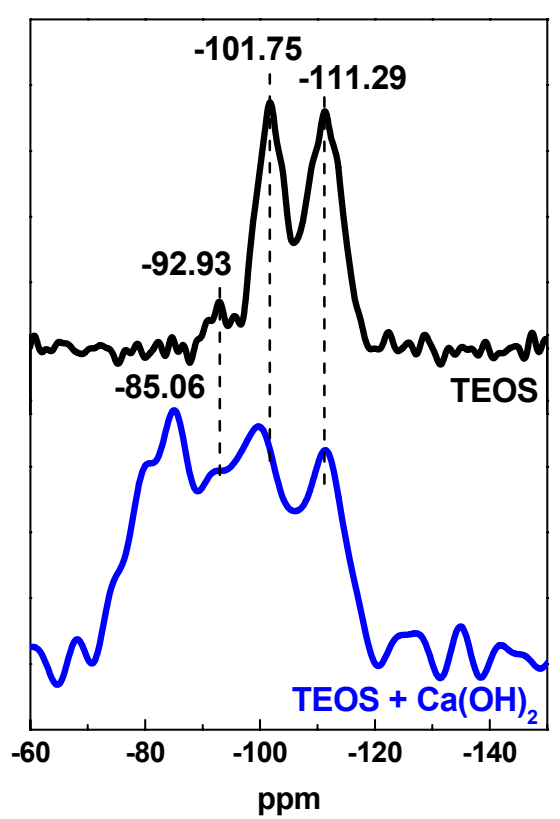

Fgure 4. ${ }^{29} \mathrm{Si}$ MAS NMR spectra for TEOS and TEOS mixed with portlandite after 45 days cured at $95 \% \mathrm{RH}$ 


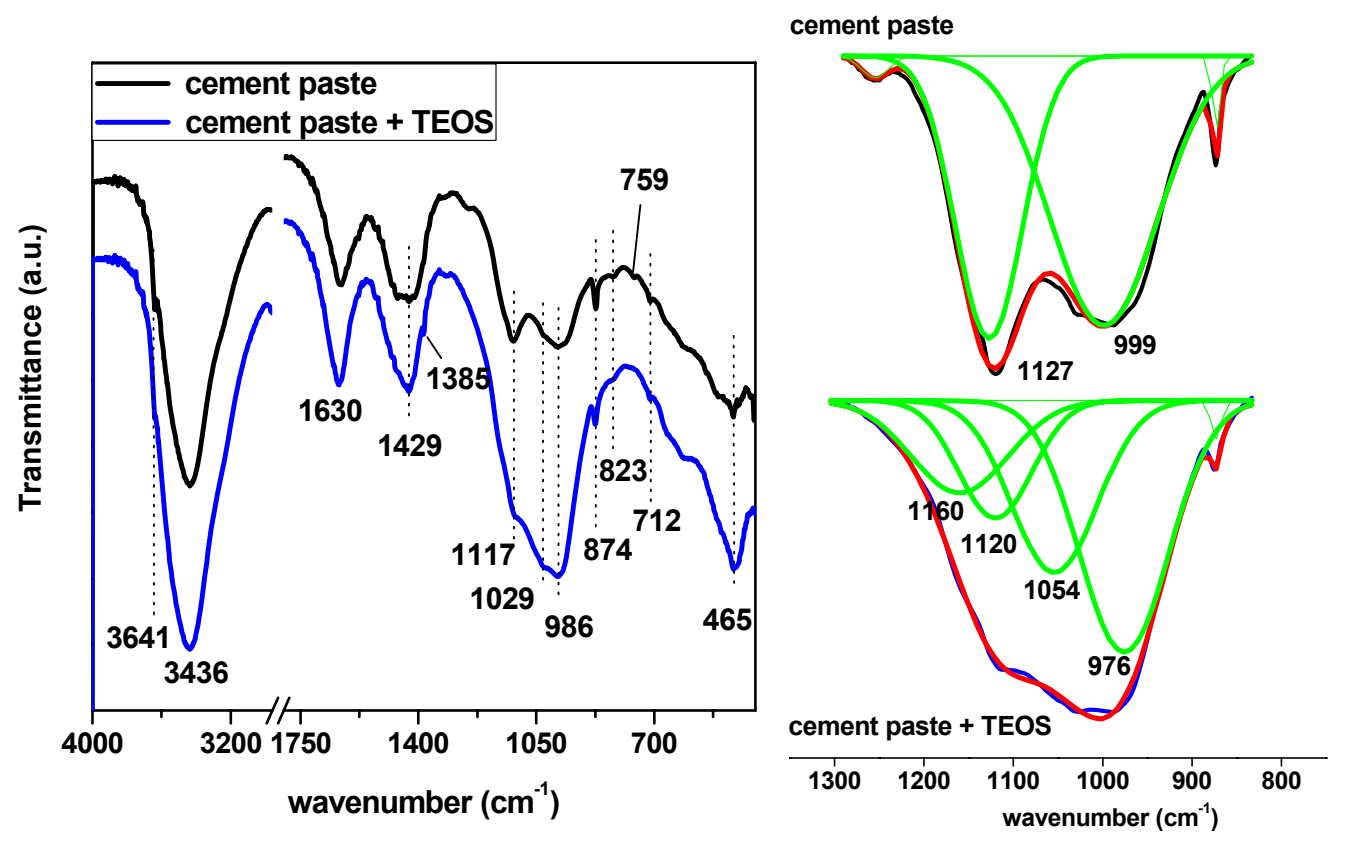

Fig. 5. FTIR spectrum for humidity chamber-cured cement paste with and without TEOS: on the right, deconvolved spectra between approximately 1300 and $800 \mathrm{~cm}^{-1}$. 


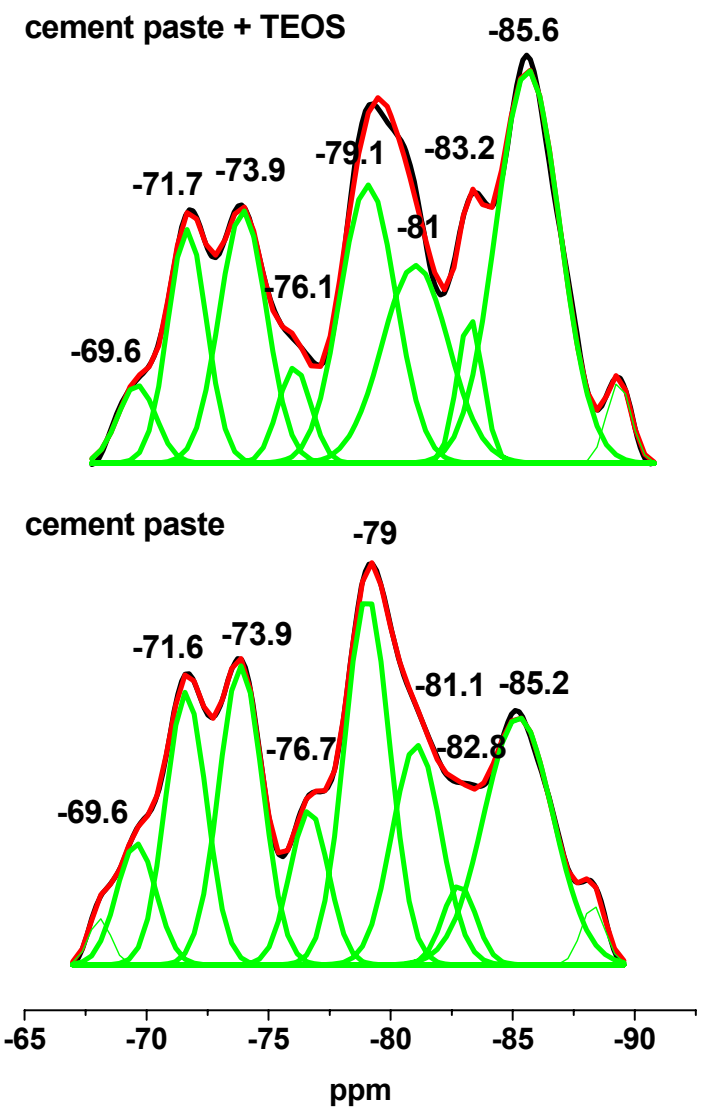

Fig. $6 .{ }^{29} \mathrm{Si}$ MAS NMR spectra for the 45-day hydrated cement paste with and without TEOS. 
